issues involved. Finally, the vital concern of all industry in Britain at the present time is export and it is here that 'International Paper Size' has come into its own. Twentysix countries are using the system for commercial and technical paperwork; these include Austria, Belgium, Denmark, Finland, Germany, Holland, Italy, Norway, Portugal, Spain, Sweden and Switzerland.

\section{Millboard Manufacture}

THE main raw material in the manufacture of millboard is waste paper, and this, like many of the other commodities used in the process, has considerably increased in price since the end of 1964. Coupled with increased wages and overheads, and the fact that many overtime hours have had to be worked in the factory at Bourne End, Bucks., due to permanent under-staffing, the price structure of the products of Jackson's Millboard and Fibre Co., Ltd., has been correspondingly increased. These and some other interesting items are disclosed in the statement of the chairman (Mr. M. W. Jackson) at the seventy-fourth annual general meeting on September 29, 1965 (Jackson's Millboard and Fibre Co., Ltd., Directors' Report and Accounts, 1965. Pp. 12. London: Jackson's Millboard and Fibre Co., Ltd., 1965). The first fully automated intermittent board-making machine in Britain was installed in the Company's main factory in 1962. In this connexion, Mr. Jackson says: "In my report in September 1964 I referred to the purchase of the board making unit from Norway, and this installation is now on the point of completion. We have also modernized one of our existing board-making units at present concerned with the production of leatherboard, and this makes our second automatic machine. It is hoped that well before the end of the year we shall have three automatic board-making units in operation at Bourne End". These innovations should help considerably to mitigate price increases and expand the Company's export trade, an important item. But in spite of all efforts to improve efficiency, including expenditure on modern plant as described, ". . . the increases in operating costs over recent months are more than we are able to bear, if we are to show a reasonable return". Thus, even an advanced state of automation in manufacture, such as is in process of achievement in this factory, would not appear to be a panacea for all the economic ills in this industry at the present time. It can only be hoped that Mr. Jackson's somewhat gloomy foreboding will be dispelled by events this year in the shape of increased turnover and export business, especially in the Far East, where interesting results of overseas visits appear already to be bearing fruit.

\section{Particle Size Measurement}

A REPORT of a meeting, held in November 1963, at the British Ceramie Research Association, Stoke-on-Trent, to consider particle size measurement, has recently been published by the British Ceramic Society on behalf of the European Ceramic Association (Pp. 20. British Ceramic Society, Shelton House, Stoke-on-Trent, August 1965. 5s.). Measurement of particle size and interpretation of results to practical advantage are common problems in the ceramic and many other industries. Recent years have seen many improvements in traditional methods of measurement, such as using the microscope and the technique of sedimentation, but methods based on new principles have also appeared. It is pointed out, however, that unfortunately none of the latter has universal application, and so diversity of method increases. At the meeting four prepared contributions formed a basis for discussion: a review of the purpose of analysis and problems involved as seen by the British Ceramic Research Association; a report on a recent classification of methods undertaken by a sub-committee of the Society for Analytical Chemistry; an assessment of the Coulter counter as a means of analysis of some ceramic materials; and an account of size analysis of clays within the submicron range. On the subject of appraisal of methods of particle size measurement now commonly publicized, some interesting results are revealed from replies to a questionnaire sent to industrial concerns, universities and colleges of technology. The questions concerned methods actually in use, type of material analysed, size-range, purpose of measurement (routine control, research, etc.). In so far as replies from 69 respondents may at this stage be considered representative, cautiously interpreted, they are certainly indicative, and fall into line with what might well be anticipated as the trend of things to-day. Summarily, sieving is the most frequently used single method; the Andreasen pipette method follows closely; sedimentation methods are generally popular; elutriation is relatively seldom used; graticules are frequently used, so also is the Coulter counter, while permeability methods receive a fair share of support. Of the 74 methods of particle size measurement in use and listed in the classification, 24 were not used by the respondents. Of the 69 replies received, 32 respondents used one method or another in routine control operations, 61 in research or development work. It is planned to organize comparative tests of some of the better-known methods on a large scale; possibly this may take the form of analysis by different laboratories of the same sample by the same method, or the analysis by the same laboratory of the same sample by different methods.

\section{Surface Active Agents}

SURFACE active agents are playing an increasingly important part in the manufacture of many diverse products in use in everyday life. These vary from materials such as oil paints and plastics, to duplicating inks and deodorants. These agents are incorporated in industrial and domestic preparations not only for their 'point of use' effect, for example, in shampoos, paint removers, etc., but also to facilitate manufacture, as in the case of emulsion paints, or to promote consistency in products such as cosmetic creams. The problem of determining the type of surface active agent present in a variety of different preparations is one constantly facing many analytical and industrial chemists, some of whom, by long experience, are experts in this field. Others, however, possibly the majority, have limited experience of these agents, and the apparatus requisite to their analysis. For the latter group, particularly, a most useful handbook has recently been published entitled Surface Active Agents : their Extraction, Characterisation and Determination, by Maurice Bell (Pp. 24. Leeds: Glovers (Chemicals), Ltd., 1965. 5s.). It is shown in this booklet that, in spite of the wide range of products of which surface active agents are important constituents, it is possible to divide such materials into a comparatively small number of groups: emulsions (oil-in-water or water-in-oil); aqueous based (that is, dissolved in water or mixtures of water and water-miscible solvents); non-aqueous based (dissolved or dispersed in oils, fats or organic solvents); and dry based (adsorbed on or admixed with powderedinorganic or organic materials, or similar in tableted or cake form). With this classification in mind, the various techniques and tests are considered under the appropriate headings: separation of the isolated surface active agents; characterization of the isolated surface active agents; quantitative examination of surface active agents; control of surface active agent concentration; chemical methods of control. The directions throughout, although to some extent summarized, are clear, concise and practical; if further detailed information on any procedure is required, then the list of references included will help. Domestic soap and detergent powders, washing-up liquids, and the like, are excluded from this booklet. They are the subject of special investigations and analytical schemes described 